\title{
ANÁLISE DA ENXAQUECA E OUTRAS SÍNDROMES DE ALGIAS CEFÁLICAS EM ADULTOS 40 A 69 ANOS NO BRASIL POR REGIÃO/UNIDADE DA FEDERAÇÃO, NO PERÍODO DE AGOSTO DE 2016 A AGOSTO DE 2020
}

\author{
ANALYSIS OF MIGRAINE AND OTHER SYNDROMES OF CEPHALICGIAS IN \\ ADULTS 40 TO 69 YEARS IN BRAZIL PER REGION/UNIT OF THE \\ FEDERATION, FROM AUGUST 2016 TO AUGUST 2020
}

Giovana Parra Pelisari*, Gabriel Henrique Azeredo, Mariana Domingos Gonçales, Cláudia Cristina Batista Evangelista Coimbra, Gustavo Bacelar Peraro.

UNINGÁ - Centro Universitário Ingá, Maringá, PR, Brasil. *giovanaparra.p@gmail.com

\section{RESUMO}

A enxaqueca ou migrânea, é familiarmente conhecida como dor de cabeça, e esta é a forma mais comum da queixa da maioria da população. A enxaqueca é uma crise de cefaleia moderada a intensa, que geralmente apresenta uma forma latejante, unilateral, e comumente acompanhada de náuseas, vômitos, de uma irresistência à luz, ruído e cheiros. A enxaqueca é um estado de cefaléia crônica primária. Pode ser determinada como uma resposta neurovascular normal que ocorre em organismos suscetíveis. Clinicamente, pode se manifestar por dores de cabeça repetidas e relacionadas a um gatilho. Nessa continuidade, o estudo tem por finalidade analisar o número de óbitos e taxa de mortalidade decorrente de enxaquecas e outras síndromes de algias cefálicas, contrapondo as faixas etárias entre 40 a 69 anos, em ambos os sexos, no intervalo de agosto de 2016 a agosto de 2020, dentre as Regiões/Unidades da Federação. Para isso, adotouse um estudo epidemiológico analítico, sendo os dados retirados do DATASUS, dando importância ao sexo, faixa etária, óbito e taxa de mortalidade. No intervalo em foco, verificou-se 198 óbitos, sendo um total de 88 óbitos masculinos e 110 óbitos femininos, tendo ambos os sexos maior incidência na Região Nordeste. $\mathrm{Na}$ faixa etária descrita entre 40-49 anos apresentou em ambos os sexos os maiores casos de óbitos novamente na Região Nordeste, porém, o maior caso de óbitos foi o sexo feminino, contabilizando 19 mortes nessa região. A faixa etária de 50-59 anos novamente apresentou o maior caso de óbitos na Região Nordeste, contando com um total de 29 óbitos, contemplando os dois sexos analisados. Na última faixa etária analisada, 50-59, teve novamente o maior número de óbitos a Região Nordeste. Especificamente na cidade de Pernambuco, em ambos os sexos estudados, encontrou-se o maior número de óbitos, porém, a maior prevalência da taxa de mortalidade, incluindo todas as faixas etárias e ambos os sexos pesquisados, foi encontrada no Amazonas. Assim, conclui-se, que a Região Nordeste apresenta os maiores números de óbitos, sendo o sexo feminino o mais acometido, tendo um decréscimo da faixa etária 40-49 anos para 50-59, porém, houve um acréscimo para a faixa etária de 60-69 anos. Pelo fato de não ter ainda exames específicos para confirmação da 
doença, o seu diagnóstico não é rápido, porém há muitos tratamentos eficazes, sendo esse adaptado a cada caso. Para tanto, imperfeições na realização de providências necessitam ser corrigidas, fazendo-se essencial a pesquisa de novos métodos para identificar mais rapidamente e de forma certeira a enxaqueca.

Palavras-chave: Cefaléia. Enxaqueca. Faixa etária. Óbitos. Taxa de mortalidade. 